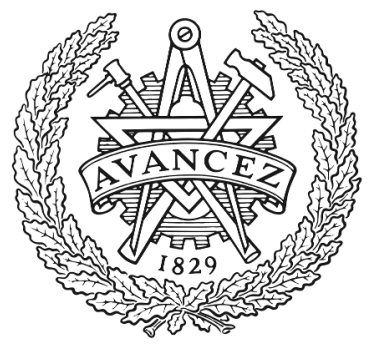

CHALMERS

UNIVERSITY OF TECHNOLOGY

\title{
Climate impact optimization in concrete bridge construction
}

Downloaded from: https://research.chalmers.se, 2023-04-26 15:30 UTC

Citation for the original published paper (version of record):

Ekström, D., Al-Ayish, N., Simonsson, P. et al (2017). Climate impact optimization in concrete bridge construction. IABSE Conference, Vancouver 2017: Engineering the Future - Report: $1161-1168$

N.B. When citing this work, cite the original published paper. 


\title{
Climate impact optimization in concrete bridge construction
}

\author{
Daniel Ekström*
}

WSP Sweden, Bridge and Hydraulic Design, Gothenburg, Sweden

Nadia Al-Ayish

CBI Swedish Cement and Concrete Research Institute, Stockholm, Sweden

\section{Peter Simonsson}

Swedish Transportation Administration, Luleå, Sweden

Rasmus Rempling

Chalmers University of Technology, Gothenburg, Sweden

*Contact: daniel.ekstrom@wspgroup.se

\begin{abstract}
Estimates indicate that the total climate impact, from a lifecycle perspective, generated by Swedish construction processes reaches the same magnitude as emissions from all passenger cars in Sweden. A large part of the emissions from construction of roads and railways arise from production of steel and concrete used in bridges and other infrastructure structures. In this research, several cases of existing concrete bridges have been investigated. The case studies are in a very firm way analyzed, and then opportunities for reducing climate gas emissions are described and elaborated upon. Accordingly, design and dimensioning through the use of today's technology and material selection are discussed. Without developing new ways to construct bridges, or comparing concrete with other materials, a useful guide on how to use technology and opportunities that are available for constructing climate smarter versions of standard bridges today is developed and described.
\end{abstract}

Keywords: climate smart; concrete bridge; optimization; sustainable construction; integrated design

\section{Introduction}

As a primary goal, the Swedish Transport Administration, (STA), has concluded that climate gas emissions from construction, operation and maintenance of the infrastructure must be reduced if Sweden should be a pioneer and to reach both national and global climate goals. This is done by setting long-term requirements for the reduction of greenhouse gas emissions from construction, operation and maintenance of infrastructure.
There are a variety of tools to make life cycle assessments (LCA) and life cycle cost estimations (LCC) of a bridge, see for example [1]. These tools are used to optimize both the environmental impact and costs during construction. Unfortunately, the models are often complex and lack transparency and therefore are rarely used in practice within infrastructure projects. In this study, it has been investigated to what extent, or how climate smart, it is possible to construct a commonly occurring concrete bridge today, merely by utilizing current norms and regulations as well as existing materials and technology. The chosen approach might be perceived as a bit 
narrow-minded and short-sighted, however, several available opportunities remain unutilized by constantly looking too far ahead. In pursuit of innovations in the construction sector, always high

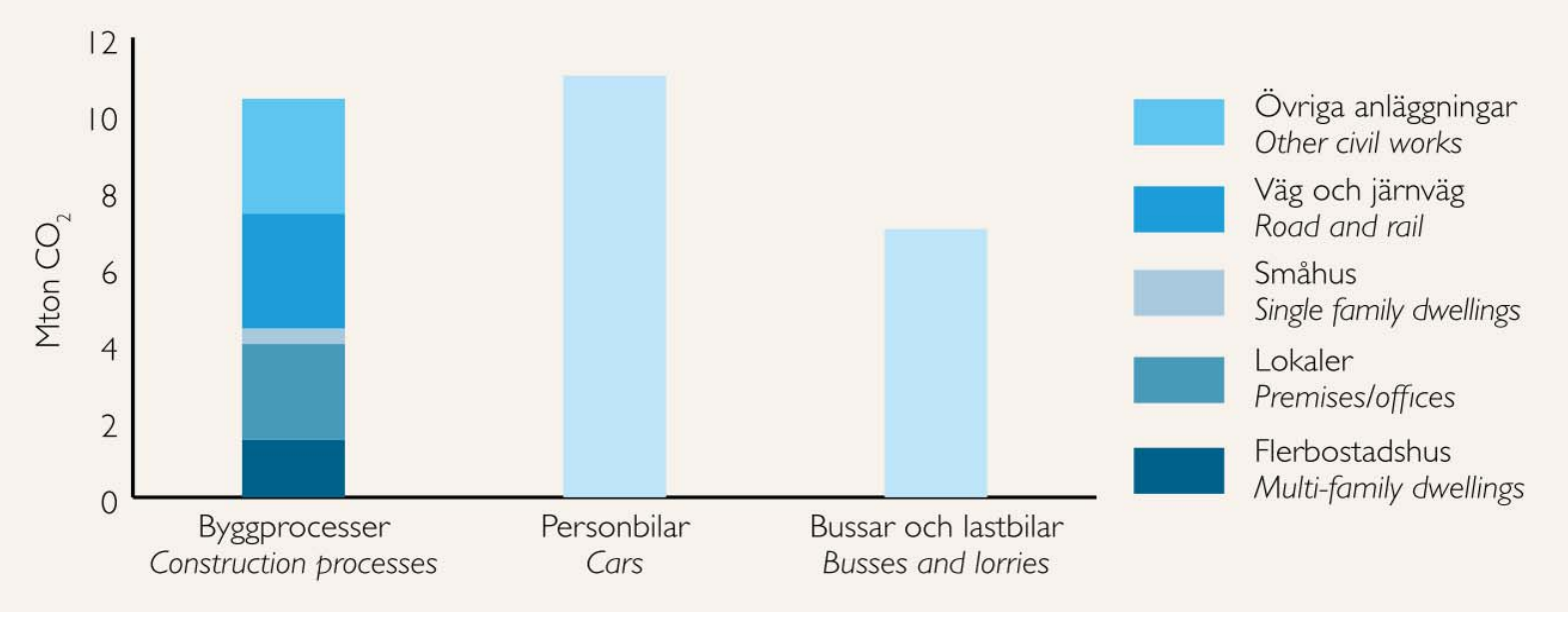

Figure 1. Climate impact from construction processes in Sweden [2]
According to Eurostat, in e.g. [3], the European constructions sector produces close to $40 \%$ of all greenhouse emissions and, above that, over its life time, buildings and civil infrastructure produce approximately a third of the total waste within the EU.

Although indicated in calculations [2], based on a life cycle perspective, the total climate impact from the construction process in Sweden reaches the same level as all the passenger cars together, Figure 1. This pre-construction effect has generally been overseen, since the primary focus in general has been on post-construction effects, such as energy losses, etc. To a great extent, the emissions from road and rail and other civil works Figure 2 is related to the production of materials we use in construction, such as construction steel, concrete and reinforcement in bridges, retaining walls and other structures. This should be a clear signal to the construction industry to work harder to lower its climate impact.

STA has acknowledged the fact that the emissions produced in construction, repair and maintenance of their infrastructure must be reduced in order to reach both the national and global climate goals and for Sweden to keep its position as a country to follow in these matters. on the agenda, perhaps it is precisely these innovations we miss out on because we fail implementation of available methods?

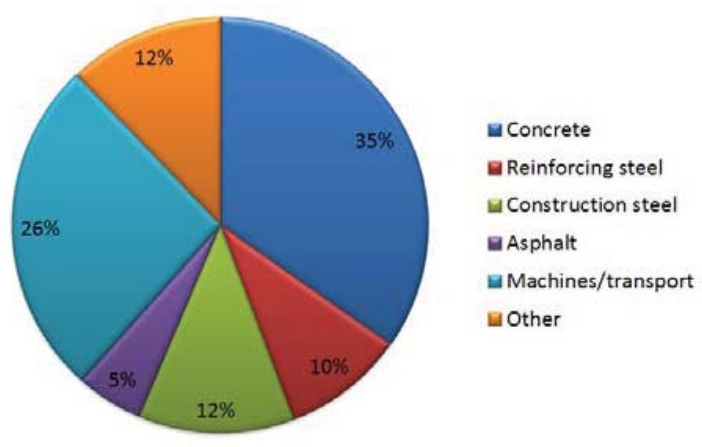

Figure 2. Distribution of emissions in the Swedish infrastructure sector [4]

STA works on a series of initiatives to increase the level of productivity and innovation in the Swedish sector of infrastructure. This is made in line with the increased commitment regarding issues of sustainability and the national plan for transportation, which extends until 2025. Based on current price development, the sector is believed to need an annual productivity improvement rate of 2-3 per cent to be able to implement everything included in the adopted plan.

Some areas which are mentioned to support this productivity improvement rate are, increased industrial thinking, use of standardized products and processes, more distinct focus regarding knowledge management in design and 
construction. In order to succeed with this objective, multiple efforts and commitment from the sector is needed aiming at closer cooperation and collaboration between different disciplines. Interference throughout the entire process of bridge construction has to be minimized, both within and between the design and construction phase. The above mentioned approaches are most probably valid also for managing climate impact issues.

\section{Approach}

In this project, the intention was to specify a typical case of structure to describe the potential for improvement by adopting a more sustainable approach to bridge construction. To find measures which are easily implemented in every-day work, it was important to find a typical case of a concrete bridge structure which represents the majority in bridge construction today. The course of action can in short be described as below:

- Identify typical case

- Identify possible measures to reduce carbon footprint by choice of materials and by design and construction

- Calculation of performance based on EPDtool from Svensk Betong ${ }^{1}$

- Identify an integrated design and construction process that can realize identified measures in relation to processes required in regulations (STA, CEEQUAL and PAS2080)

- Compilation of advice and guidance

\subsection{Identifying typical cases of concrete bridge structures in Sweden}

As a result from one of their productivity initiatives, STA has identified several product categories that are considered particularly suitable for industrial and serial construction [5]. One of these product categories consist of bridges that are considered particularly suitable for industrial

\footnotetext{
${ }^{1}$ Svensk Betong is an industry association within the concrete industry in Sweden. www.svenskbetong.se
}

and serial construction. These bridges are generally characterized as smaller bridges with a span length less than $20 \mathrm{~m}$, relatively low geometrical complexity, and with a limited skewness.

This category of bridges is the most commonly built in Sweden and the scope for this project therefor fits that product category very well. In terms of numbers, bridges with a span under $20 \mathrm{~m}$ is dominated by the slab frame bridge which constitutes about $46 \%$ of the total portfolio, second followed by the soil steel composite bridge at $28 \%$. Out of the remaining bridges, the slab bridge is the only bridge which constitutes a major proportion, $14 \%$, even though this bridge is built less now. All single-span bridges in Sweden less than $20 \mathrm{~m}$ are distributed according to Table 1.

Table 1. No. of bridges less than $20 \mathrm{~m}$ in Sweden.

\begin{tabular}{|c|c|c|}
\hline \multicolumn{3}{|c|}{ No. of bridges $<=20 \mathrm{~m}$} \\
\hline Slab frame bridge & 5681 & $46 \%$ \\
\hline Soil and steel composite bridge & 3455 & $28 \%$ \\
\hline Slab bridge & 1752 & $14 \%$ \\
\hline Vault bridge & 932 & $7 \%$ \\
\hline Beam bridge & 376 & $3 \%$ \\
\hline Beam frame bridge & 247 & $2 \%$ \\
\hline Arch bridge & 3 & $0 \%$ \\
\hline Other & 3 & $0 \%$ \\
\hline Total & 12449 & $100 \%$ \\
\hline
\end{tabular}

\subsubsection{Single-span slab frame bridges}

The single-span slab frame bridge has a typical design and parts according to Figure 3 . What separates it from the simple frame bridge is generally the monolithic connection between the slab and the vertical frame legs. By its configuration the structure requires no bearings or expansions joints, normally leading to considerable savings in both construction and maintenance costs [6]. One if its disadvantages is the restraining forces and moments that appear by, for example, shrinkage and temperature variations.

Given the distribution of built single-span slab frame bridges, the project limited the scope of cases to bridges in the span intervals between 5$10 \mathrm{~m}$ and $15-18 \mathrm{~m}$. All investigated bridges are resting on a foundation of compacted fill. 


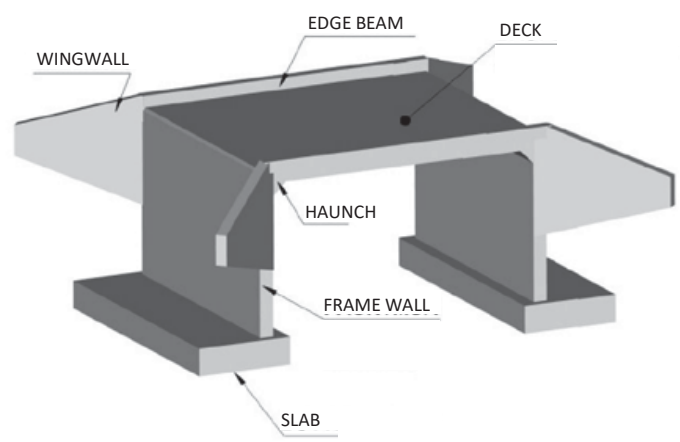

Figure 3. Single-span slab frame bridge [7]

\subsection{Limitations in design}

\subsubsection{Technical requirements and regulations}

Opportunities for climate impact reducing measures are strongly related to the existing boundaries defined in the regulatory framework. An overview of the prevailing regulatory framework has therefor been conducted. The intention of a regulatory framework is usually to act as guide during the process to support the user to fulfill all necessary requirements in its delivery regarding load bearing capacity, stability, durability and safety. Requirements stated in codes and standards although need to be recognized as the minimum quality acceptable for the structures treated, i.e. the societal demands for quality. Up to date, there has been no real support in how to establish a sustainable design and construction, even though LCC and LCA are starting to be commonly used, see e.g. [1].

Presented in Figure 4, is a graphical representation of the hierarchy between technical regulations applied by STA today. The regulatory framework consists of, due to its nature, many limitations but there are also opportunities for change and deviation. The pyramid is divided in several layers which also represents the level of importance of the included documents. From agency regulations at the top to acceptable, knowledge and experience based, solutions at the bottom. Here it is important to understands that the lower levels in the pyramid can be stricter in requirements than given above. One such aspect is the requirements for concrete.

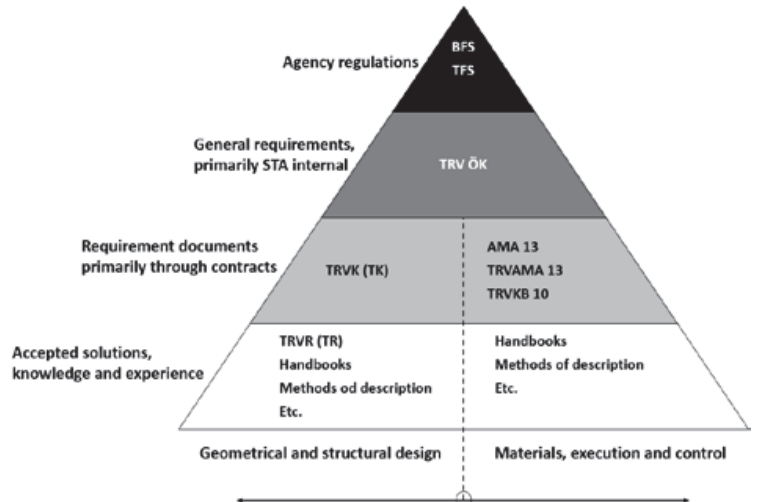

Figure 4. Pyramid of rules applied by STA

STA has since the mid 1980's adopted a quite restrictive approach to the use of additives in concrete, e.g. fly-ash and slag. Over the last 15 years, requirements for concrete in bridges and tunnels owned by STA, are more stringent than the requirements stated in Swedish Standards, e.g. SS-EN 137003 [8]. Based on the increased knowledge regarding durability of concrete gained from research and international experience, this view has changed and, consequently, also the future use of additives. Therefore, for this study, the possible measures have been examined based on what is allowed in Swedish Standards.

\section{Measures for reducing climate impact}

The possible measures to reduce $\mathrm{CO}_{2}$ are divided into two categories; measures related to materials and measures related to design and construction. The measures are identified by the project through a task group with a great range of knowledge in processing of concrete and concrete structures. For this article, only a few of all considered measures are treated, see Table 2.

\subsection{Measures related to material}

On the material side, a large impact can be made only through simple and available choices, such as supplier, use of additives, utilized strength class for the concrete, etc.

In the calculations, all based on available and valid EPD for each product, the lifecycle considerations of the products are from cradle to gate, meaning that transportation from the distributor to the 
actual site is added. The information contained in EPD is based on LCA, with the intention to cover different stages in the life cycle. The format of EPD is supported by European Standard EN 15804 which provides rules to ensure that all EPDs of construction products, services and processes are harmonized, see e.g. [1].

Table 2. Summary of measures for reducing climate impact

\begin{tabular}{|c|c|c|c|}
\hline \multicolumn{2}{|c|}{ Materials } & \multicolumn{2}{|c|}{ Design and construction } \\
\hline Concrete & Supplier & Transportation* & Distance \\
\hline & Additives & & Modes \\
\hline & Strength class & Design & Optimization \\
\hline \multirow[t]{5}{*}{ Reinforcement } & Supplier & & Aesthetics \\
\hline & Solution & Construction & Methods \\
\hline & & Service life ${ }^{*}$ & Repair and maintenance \\
\hline & & & Restauration \\
\hline & & & Reuse and recycling ${ }^{* *}$ \\
\hline
\end{tabular}

* Measures related to transportation and service life are not exclusively treated in this article.

${ }^{* *}$ For the reuse and recycling an increased carbonation normally can be accounted for]. This has not been treated exclusively in this project.

Table 3. Calculated performance of individual measures

\begin{tabular}{|c|c|c|c|}
\hline & \multicolumn{2}{|c|}{ Climate impact } \\
\hline Measure & Average & Max & Min \\
\hline No action* & 0 & 0 & $-8 \%$ \\
\hline Cement - supplier & & $-6 \%$ & $11 \%$ \\
\hline lowest & $-7 \%$ & $14 \%$ & $-10 \%$ \\
\hline highest & $13 \%$ & & $-11 \%$ \\
\hline Cement - additives & & $-8 \%$ & $-15 \%$ \\
\hline slag 20\% & $-10 \%$ & $-8 \%$ & $-15 \%$ \\
\hline fly-ash 20\% & $-10 \%$ & $-12 \%$ & $-21 \%$ \\
\hline slag 35\% (fully or partly) & $-13 \%$ & $-13 \%$ & \\
\hline slag 35\% (fully, according to TCG ${ }^{* *}$ ) & $-13 \%$ & $-16 \%$ & $-27 \%$ \\
\hline Reinforcement - supplier & $-19 \%$ & & $-9 \%$ \\
\hline low & & $-15 \%$ & $26 \%$ \\
\hline European average & $-19 \%$ & $-5 \%$ & \\
\hline unknown origin & $-6 \%$ & $46 \%$ & \\
\hline
\end{tabular}

*No action; refers to a reference case with values for concrete normally used by STA in LCA.

**TCG, Tomas Concrete Group

In Table 3, the independent numbers from each of the calculated measures are presented. The table presents a calculated average for all evaluated bridges, as well as the maximum and minimum value obtained.

For the reinforcement, the variation is mainly related to the origin of the steel, recycled steel scrap or virgin steel. The difference between the two is large in $\mathrm{CO}_{2}$ emissions, in favor of the steel scrap due to the use of electricity in the process instead of fossil fuel used for the virgin steel. A European average for the steel is used in this study as a reference. The cement used by STA in Swedish infrastructure is normally without any additives. By adopting the possibilities given in regulation, in some cases, up to $35 \%$ of the cement can be replaced by additives. 
The decrease or increase by the different measures are set into relation to a "normal concrete" used by STA in LCA analysis.

By adding the different measures, it is possible to generate a total carbon footprint reduction of between $40-50 \%$ compared with the normal case. Alarmingly, by doing the "wrong choices" the total carbon footprint can increase by approximately the same numbers, Table 4.

Table 4. Calculated performance of combinations for concrete

\begin{tabular}{|c|c|c|c|}
\hline Combination - concrete & Average & Max & Min \\
\hline min cement, max additive, min concrete class & $-22 \%$ & $-17 \%$ & $-27 \%$ \\
\hline min concrete class, max additive & $-15 \%$ & $-11 \%$ & $-18 \%$ \\
\hline min cement, max additive & $-19 \%$ & $-17 \%$ & $-22 \%$ \\
\hline Measure - lowest possible (to standard) & $-41 \%$ & $-33 \%$ & $-48 \%$ \\
\hline Measure - highest possible (to standard) & $46 \%$ & $57 \%$ & $40 \%$ \\
\hline
\end{tabular}

\subsection{Measures related to design and construction}

\subsubsection{Design optimization}

There has always been a strong belief amongst designers that, if given the time and opportunity, reduction of materials and optimization of structures would be possible. Unfortunately, this has been difficult to quantify in any way, but there are several indications that there is a large potential here. Based on the results from studies of parametric design $[9,10]$, at least a $20 \%$ reduction in both material cost and $\mathrm{CO}_{2}$ equivalent emissions, seems quite reasonable to assume. Parametric design enables an evaluation of a large number of alternatives within given requirements. The approach needs an automated design process [11] but, in return, provides a basis for informed decisions.

Figure 5 exemplifies the distribution of climate impact by the different parts and by materials. In general, the results show that the contribution from the concrete is dominating. In design, the traditional approach in optimization of reinforced concrete is to utilize the materials to a maximum. This is normally done by utilizing the maximum allowed effective height of the member in order to minimize the amount of reinforcement. Instead, by using the allowed space in regulations, it is e.g. possible to increase the amount of reinforcement to decrease the amount of concrete. For the studied bridges, in most cases, this is leading to reduced $\mathrm{CO}_{2}$ emissions.

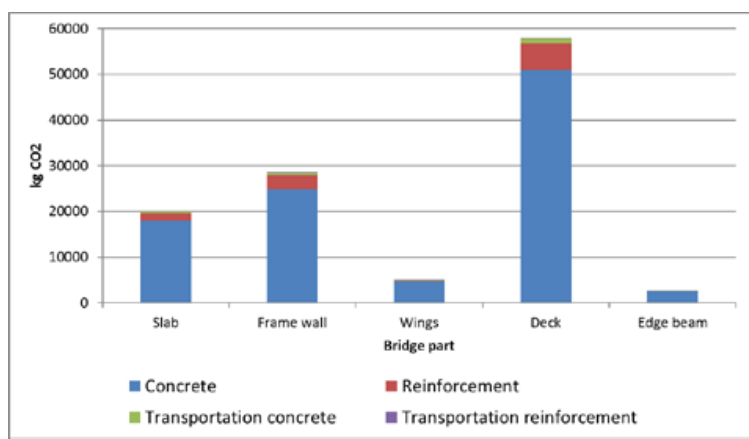

Figure 5. Distribution of $\mathrm{kg} \mathrm{CO} \mathrm{CO}_{2}$ by parts and materials

\subsubsection{Aesthetics}

Aesthetics can be utilized in different ways in structural design, which can have both positive and negative climate impact.

The positive effect can be achieved when the aesthetics is incorporated with the structural design, giving the structure an optimal shape based on the load it is designed to carry. For small bridges, within the scope of this project, this approach is rarely adopted to the fullest. To use haunches at the supports or a parabolic shape for the superstructure is normally the way. Due to construction issues these aspects may be overlooked based on economic reasons.

The negative effect can be realized, for example, when additional concrete is used to create surface effects. This additional concrete layer gives no added value to the structural behavior. 


\subsubsection{Construction methods}

There are few ways to build an ordinary singlespan frame bridge, and in Sweden the most common approach is cast in-situ. This is in one way related to the benefits from having a monolithic construction, and in a second way the local and national traditions. Prefabricated slabframe bridges are very unusual in Sweden even though the conditions for the market have improved and the numbers of prefabricated bridges are starting to grow. The choice of structure and construction methods are of course strongly connected, and there are many advocates for increasing the use of prefabricated bridges and elements. However, the large-scale benefits in climate impact reduction is not a consequence of the choice between prefabrication or cast in-situ. These effects are first seen in relation to faster construction and less disturbance at construction site.

\section{Discussion}

This study shows that using EPDs in calculations is an effective way in raising the environmental awareness in design and to decrease the environmental impact of structures. By addressing the possibilities to use cement additives and choose reinforcement based on valid information, there is a large gain to realize for a relative small effort. However, up to date, EPD is not an obligatory declaration for producers to have. It is up to the national authorities to ask for this or to set it as a requirement in procurement.

In traditional design and construction, the primary focus is normally on cost, time and performance objectives. The process is usually presented as linear and therefore also experienced as inefficient and resource-intensive, both in the use of human and natural resources. Over the years though, literature e.g. $[12,13]$ claims that we stand in front of a paradigm shift, where the current unsustainable linear development must stand aside for a new way of thinking. Until the environmental measures are used in construction in the same manner as cost, time and performance, stating environmental requirements might ensure that the structure will have a lower $\mathrm{CO}_{2}$ impact.
To generate a sustainable construction process, a long-term perspective needs to be applied to each project and putting the built infrastructure into the context of the natural environment instead of a separate object. This type of life cycle consideration needs to be adopted by designers, constructors and clients to create this paradigm shift.

Within structural design there are several basic requirements of mechanical design that needs to be fulfilled, such as structural resistance, serviceability, durability and robustness. These are all requirements of structural performance which are taken for granted without putting it into the context of sustainability. To implement sustainable development fully in an organization or project group, it is highly important that both the decision making and content of structural performance, economy and environment are broken down to different levels. Such levels can be at organization, project or individual level $[11,14]$. Also, a fourth level can be added representing technology development, such as a seamless information flow and design methodologies that investigate thousands of design alternatives. By investigating and optimizing design alternatives, it is possible to assess the sustainable impact on a more detailed level. However, in order to make this an effective process the routine design tasks need to be automated [9-11]. The use of information and communication technologies (ICT) will play an important role by generating a continuous flow of information, which increases the transparency of projects and minimizes the risk for loss of information.

\section{Summary and conclusions}

By combining the efforts and knowledge from all involved parties, stakeholders and disciplines from early stages it is evident that a large reduction of the climate impact of concrete bridge construction can be obtained. Several steps are needed to be taken in order to create a change within the Swedish infrastructure sector.

Infrastructure, such as bridges, is commonly designed for a service-life as long as 120 years which of course means that its life cycle mainly 
constitutes of issues related to post-construction stages. All stages after realization are greatly dependent on, and constrained by, decisions made during design and construction of the structure. It is of great importance to have designers and constructors with a sustainable approach, however it is equally important that the client takes their share of responsibility by creating the opportunity and space for the designers and constructors to operate in. This could include changes to the regulatory framework, norms and design codes, and by the choice of procurement practices and clearly specifying the requirements. STA, being the single most important client in infrastructure in Sweden, has a great responsibility in eliminating barriers that might hinder application of a cradle-to-graveto-cradle approach.

First, an environment for collaborative efforts needs to be established by the client.

Secondly, the client also needs to establish the requirements which will push the industry forward.

Thirdly; the industry needs to shoulder the responsibility when given the opportunity. It is time to stop hiding behind short-term goals, old traditions and begin to practice what is preached.

\section{Acknowledgement}

This project was founded by SBUF, the Swedish Construction Industry's organization for research and development, and the Swedish Transportation Administration together with the following companies: Skanska, WSP, NCC, Celsa, Cementa, Thomas Concrete and Strängbetong. Special thanks are directed to the following individuals for their contribution to the result of this project: Stefan Uppenberg, Ulf Liljenroth, Jan Olofsson, Johan Söderquist, Bodil Wilhelmsson, Anders Lindvall, Jonas Magnusson, Jan Werdelin and Åsa Lindgren.

\section{References}

[1] fib Bulletin 71, Integrated life cycle assessement of concrete structures. 2013.

[2] Sveriges Byggindustrier and IVA, Klimatpåverkan från byggprocessen. 2014.
[3] R. Landolfo, L. Cascini, and F. Portioli, "Sustainability of steel structures: Towards an integrated approach to life-time engineering design," Front. Archit. Civ. Eng. China, vol. 5, no. 3, pp. 304-314, 2011.

[4] WSP, Klimat- och energikalkyl för Nationell Transportplan 2014 - 2025. 2013.

[5] Trafikverket, "Produktivitetsprogram Broar av seriekaraktär," 2014. .

[6] H. Sundquist, Infrastructure structures. Civil and Architectural Engineering Kungliga Tekniska högskolan (KTH), 2008.

[7] Trafikverket, Kodförteckning och beskrivning av brotyper. 2008.

[8] Trafikverket, Översyn av krav på cement och tillsatsmaterial i broar och liknande byggnadsverk. 2012.

[9] D. Tarazona and S. Luis, "Applicability of Set-Based Design on Structural Engineering," Chalmers University of Technology, Master Thesis, 2014.

[10] J. Difs and F. Karlsson, "Preliminärdimensionering av plattrambroar med parallelliserade FEManalyser enligt SBD," Chalmers University of Technology, Master Thesis, 2015.

[11] R. Rempling, D. Fall, and K. Lundgren, "Aspects of Intergrated Design of Structures: Parametric Models, Creative Space and Linked Knowledge," Civ. Eng. Archit., vol. 3, no. 5, pp. 143-152, 2015.

[12] N. Larsson, "The Integrated Design Process ; History and Analysis," Int. Initiat. a Sustain. Bult Environ., pp. 1-16, 2009.

[13] R. Owen et al., "Challenges for Integrated Design and Delivery Solutions," Arch. Eng. Des. Manag., vol. 6, no. 4, pp. 232-240, 2010.

[14] D. Ekström, R. Rempling, P. Simonsson, and M. Plos, "Integrated project teams in early design stages - Key variables influencing cost effectiveness in bridge building," in 19th IABSE Congress Stockholm, 21-23 September 2016, 2016. 